\title{
Radar studies of the vertical distribution of insects migrating over southern Britain: the influence of temperature inversions on nocturnal layer concentrations
}

Article

Published Version

Copyright Bulletin of Entomological Research published by Cambridge University Press (http://journals.cambridge.org/action/displayJournal?jid=BER).

Reynolds, D.R., Chapman, J.W., Edwards, A.S., Smith, A.D., Wood, C. R., Barlow, J. F. and Woiwod, I.P. (2005) Radar studies of the vertical distribution of insects migrating over southern Britain: the influence of temperature inversions on nocturnal layer concentrations. Bulletin of Entomological Research, 95 (3). pp. 259-274. ISSN 0007-4853 Available at https://centaur.reading.ac.uk/1632/

It is advisable to refer to the publisher's version if you intend to cite from the work. See Guidance on citing.

Published version at: http://journals.cambridge.org/action/displayAbstract?fromPage =0nline \&aid=869664

Publisher: Cambridge University Press

Publisher statement: Copyright Bulletin of Entomological Research published by Cambridge University Press.http://journals.cambridge.org/action/displayJournal? jid=BER

All outputs in CentAUR are protected by Intellectual Property Rights law, including copyright law. Copyright and IPR is retained by the creators or other copyright holders. Terms and conditions for use of this material are defined in 
the End User Agreement.

www.reading.ac.uk/centaur

\section{CentAUR}

Central Archive at the University of Reading

Reading's research outputs online 


\title{
Radar studies of the vertical distribution of insects migrating over southern Britain: the influence of temperature inversions on nocturnal layer concentrations
}

\author{
D.R. Reynolds ${ }^{1 *}$, J.W. Chapman ${ }^{2}$, A.S. Edwards ${ }^{4}$, \\ A.D. Smith ${ }^{2}$, C.R. Wood ${ }^{3}$, J.F. Barlow ${ }^{3}$ and I.P. Woiwod ${ }^{2}$ \\ ${ }^{1}$ Natural Resources Institute, University of Greenwich, Central Avenue, \\ Chatham, Kent, ME4 4TB, UK: ${ }^{2}$ Rothamsted Radar Entomology Unit, Plant \\ and Invertebrate Ecology Division, Rothamsted Research, Harpenden, \\ Hertfordshire, AL5 2JQ, UK: ${ }^{3}$ Department of Meteorology, University \\ of Reading, Earley Gate, Reading, Berkshire, RG6 6BB, UK: ${ }^{4}$ PO Box 203, \\ Malvern, Worcestershire, WR14 1WQ, UK
}

\begin{abstract}
Insects migrating over two sites in southern UK (Malvern in Worcestershire, and Harpenden in Hertfordshire) have been monitored continuously with nutating vertical-looking radars (VLRs) equipped with powerful control and analysis software. These observations make possible, for the first time, a systematic investigation of the vertical distribution of insect aerial density in the atmosphere, over temporal scales ranging from the short (instantaneous vertical profiles updated every $15 \mathrm{~min}$ ) to the very long (profiles aggregated over whole seasons or even years). In the present paper, an outline is given of some general features of insect stratification as revealed by the radars, followed by a description of occasions during warm nights in the summer months when intense insect layers developed. Some of these nocturnal layers were due to the insects flying preferentially at the top of strong surface temperature inversions, and in other cases, layering was associated with higher-altitude temperature maxima, such as those due to subsidence inversions. The layers were formed from insects of a great variety of sizes, but peaks in the mass distributions pointed to a preponderance of medium-sized noctuid moths on certain occasions.
\end{abstract}

Keywords: Migration, vertical-looking radar, nocturnal insect layers, temperature inversion, Noctuidae

\section{Introduction}

Long-distance windborne migration is a feature of the life-cycle of many insect taxa (Johnson, 1969; Pedgley, 1982; Drake \& Gatehouse, 1995; Dingle, 1996; Gatehouse, 1997). These species exhibit behavioural adaptations which, at a certain point (or points) in the life-cycle, cause them to

*Fax: $+441634883379 / 880066$

E-mail: D.Reynolds@greenwich.ac.uk ascend to heights where the wind speed exceeds their own powered forward speed, and they are transported downwind sometimes over considerable distances (tens to hundreds of kilometres). Windborne movement does not imply that migrants are merely inert particles at the mercy of the wind. Indeed, even quite small insects such as aphids have appreciable fall speeds, and so they can return to earth relatively quickly in the absence of persistent wing-beating (Thomas et al., 1977), particularly in absence of strong convective up-draughts (Browning, 1981). Nevertheless, it is evident that atmospheric structure has a considerable 
influence on the distribution of insects flying at altitude as is graphically shown by the various layers, line-echoes, cellular patterns and other concentrations revealed by entomological (Schaefer, 1976; Drake \& Farrow, 1988; Reynolds \& Riley, 1997) and meteorological (Gossard \& Strauch, 1983; Sauvageot \& Despaux, 1996; Russell \& Wilson, 1997, 2001) radar studies.

One frequently observed distribution occurs when the vertical profile of insect aerial density becomes highly stratified, with insects accumulating in well-defined layers at various altitudes (see references in Vaughn, 1985; Drake \& Farrow, 1988; Drake \& Rochester, 1994; Gatehouse, 1997). The aerial density in these layers is frequently one or two orders of magnitude higher than densities above and below the layer. Some, but by no means all, of the night-time insect layers are closely associated with a surface temperature inversion and examples have been described from various parts of the world, for example, Asia (Mel'nichenko, 1936; Feng et al., 2003, 2004), North America (Schaefer, 1976; Greenbank et al., 1980), Australia (Drake \& Farrow, 1983; Drake, 1984, 1985) and Africa (Schaefer, 1976; Riley \& Reynolds, 1979; Reynolds \& Riley, 1997). (A temperature inversion is defined here as an atmospheric layer in which the temperature of the air increases with altitude: a 'surface inversion' is usually caused by radiative cooling of surface air on clear nights.) The concentrations of large numbers of insect migrants into a relatively narrow altitude range can have significant implications for the distance and direction travelled. In fact, lack of information on the precise height of migratory flight can easily lead to misinterpretation of particular migrations, leading to errors in the determination of source and sink areas identified by trajectory analysis. For example, the top of the night-time inversion is often associated with a wind speed maximum in the atmospheric boundary layer, and thus much faster insect displacements can occur there than at other flight altitudes (Drake, 1985; Drake \& Farrow, 1988).

The vertical distribution of insects in the air can be studied by aerial trapping (e.g. Johnson, 1969), but the use of this technique alone is not ideal for investigating insect layering because, in practice, samples are not taken simultaneously over all flight heights, traps are often changed infrequently, and it can take a long time to catch significant numbers of the species of interest. The introduction of the azimuthally-scanning X-band radars for entomological observations (Schaefer, 1976; see the Radar Entomology Website: http://www.ph.adfa.edu.au/a-drake/trews/) allowed large volumes of air to be scanned rapidly for individual insect targets (at least for the larger species) and height/ density profiles could be determined in approximately 10-20 min, i.e. usually before the profile had time to change. Much of our knowledge of the insect layering phenomenon has been derived from the use of these radars (see reviews in Vaughn, 1985; Drake \& Farrow, 1988; Drake \& Rochester, 1994; Reynolds \& Riley, 1997).

Scanning entomological radars are usually manually operated and therefore unsuitable for observations over extended periods. They are now tending to be replaced by vertical-looking systems (VLRs) with rotating linear polarization and beam nutation (Smith et al., 2000; Drake, 2002; Chapman et al., 2003) because the latter are particularly amenable to computerized data extraction and analysis procedures, and thus they can operate unattended for long periods, but also because the new systems provide more information on the identity of the detected targets. VLRs seem particularly well-equipped to observe rapidly evolving density profiles of insects because they can simultaneously record insect targets (provided they weigh more than a few milligrams) within a number of altitude bands which together cover the expected flight heights of the migrants, and they can repeat this measurement at frequent intervals. Notwithstanding the advantages of the new VLR systems, any additional information on the identity of the radardetected insects which can be obtained by aerial trapping is, of course, very helpful (Chapman et al., 2002b, 2004).

Until the start of our programme to continuously monitor migrating insects with the VLR technique (Smith et al., 2000; Chapman et al., 2003), there were virtually no radar observations made from an entomological perspective in the UK, or indeed in Europe in general, because the British radar entomology groups had very largely worked outside Europe (Schaefer, 1976; Reynolds \& Riley, 1997). Some radar observations of insect-like targets had been made by radar meteorologists in Europe, particularly Ottersten's (1970) work using a $10 \mathrm{~cm}$ vertically-pointing radar in Sweden which appears to be one of the few long-term European radar studies of the stratification of day-time insect activity. Ottersten plotted the height distribution, between 500 and $2000 \mathrm{~m}$ above ground, of day-time point-targets (thought to be mainly attributable to insects) for each half-monthly period from mid-April to mid-September 1963, and showed that activity was greatest in July and August, and that there was a distinct maximum in the vertical distribution between about 600 and $900 \mathrm{~m}$ in these months. Stratification on individual days could be more complex, however, with two or three layers present (Ottersten, 1970). Thin stratiform daytime layers of echoes, largely due to insects, occurring at heights from about $750 \mathrm{~m}$ up to $2500 \mathrm{~m}$, were detected by Campistron (1975) with a vertically-pointing $8.6 \mathrm{~mm}$ radar in central France. The echo layers were apparently related to zones of local stability (inversions or isothermal layers) occurring above the surface convective layer, and they were disrupted if penetrative convection reached the height at which they were situated. Rather similar insect layers had been observed with a $10 \mathrm{~cm}$ FM-CW (frequency modulated, continuous wave) radar in California (Richter et al., 1973). Lastly, Sauvageot \& Despaux (1996), using an $8.6 \mathrm{~mm}$ polarimetric Doppler radar, observed bands of insects forming along the Atlantic coast of France during the afternoon and evening: the bands appeared to be associated with the local coastal wind circulation.

Notwithstanding these meteorological reports, there was evidently a need for entomologically-oriented studies in Europe of high-altitude insect layers, particularly those occurring after dark (the examples discussed in Campistron and Ottersten refer mainly to daytime layers). In this initial paper, the methodology developed to investigate insect layer concentrations is outlined, and brief descriptions are given of the incidence and general characteristics of the layers over southern Britain as revealed by the VLRs. Some case studies of pronounced night-time layers, and the influence on these of meteorological factors, are then presented.

\section{Methods}

A nutating vertical-looking radar (VLR) was operated continuously at the former Natural Resources Institute (NRI) Radar Unit laboratory at Malvern, Worcestershire 


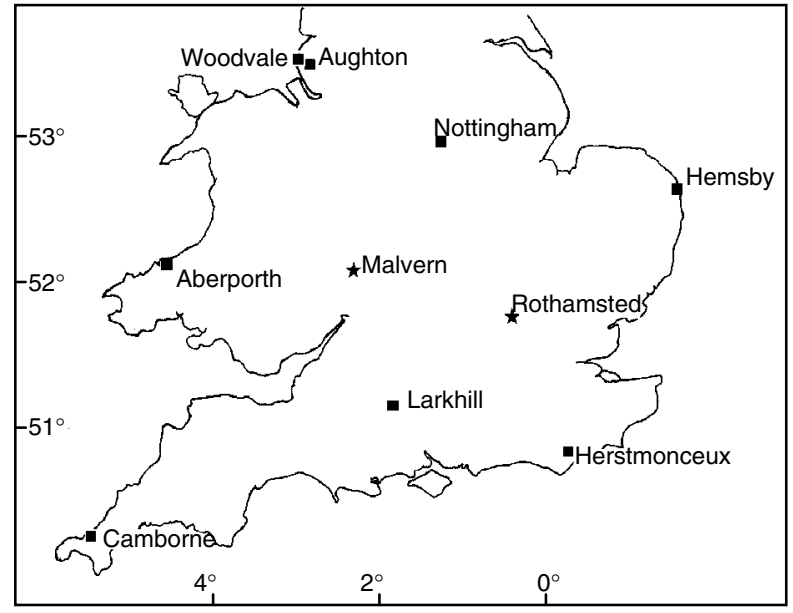

Fig. 1. Map of southern Britain showing location of the two radar sites $(\star)$, and radio-sounding stations $(\boldsymbol{\square})$ referred to in text.

(lat. $52^{\circ} 7^{\prime} 54^{\prime \prime} \mathrm{N}$, long. $2^{\circ} 19^{\prime} 55^{\prime \prime} \mathrm{W}$, c. $86 \mathrm{~m}$ asl) (fig. 1) between July and September 1995 and between October 1999 and September 2001. During the last mentioned month, the radar was moved to a nearby site in Malvern (the Defence Science and Technology Laboratory (DSTL) site: lat. 52 $06^{\prime} 04^{\prime \prime} \mathrm{N}$, long. $2^{\circ} 18^{\prime} 38^{\prime \prime} \mathrm{W}$, c. $59 \mathrm{~m}$ asl). Since May 1999, another VLR has been operated continuously at Rothamsted, Harpenden (lat. $51^{\circ} 48^{\prime} 32^{\prime \prime} \mathrm{N}$, long. $0^{\circ} 21^{\prime} 27^{\prime \prime} \mathrm{W}$ ) (c. $120 \mathrm{~m}$ asl).

\section{Radar analysis procedures}

Details of the radar equipment and principles of operation are described in Chapman et al. (2002a, 2003) and Smith et al. (1993, 2000). Briefly, targets flying in a given altitude range above the radar are interrogated when they pass through the vertically-pointing beam within a number of height bands ('range gates') each $45 \mathrm{~m}$ deep, separated from each other by non-sampling intervals of $26 \mathrm{~m}$. Some details of the radar sampling heights and times varied between the 1995 season and the seasons from 1999 onwards (see table 1). Data are collected for $5 \mathrm{~min}$, and before the start of the next collection period the signals are automatically analysed using an iterative procedure based on components of their complex Fourier transformations (Smith et al., 1993). Sometimes this analysis fails to converge to a solution. Most of these 'fails' are evidently caused by atmospheric precipitation, and in fine weather they comprised only a small percentage of cases (Smith et al., 2000; Chapman et al., 2002a; and see Results below). Usually, the majority of signals are resolved, and the analysis procedure yields the horizontal speed, displacement direction, orientation (body alignment), and three radar scattering parameters of the target (from which body mass and shape factors may be calculated). The extracted parameters are then used to create a simulated signal, and the correlation between the simulation and the actual radar return provides a quantitative estimate of how well the parameter extraction routine has worked (Smith et al., 1993). A high correlation coefficient (e.g. >0.9) shows that the measured signal is very well described by the underlying analysis model, and that quantities such as the
Table 1. Vertical-looking radar settings in different years.

\begin{tabular}{lcc}
\hline & 1995 & 1999 onwards \\
\hline Number of range gates & 13 & 15 \\
Altitude range & $150-1047 \mathrm{~m}$ & $150-1189 \mathrm{~m}$ \\
Sampling period & $5 \mathrm{~min}$ & $5 \mathrm{~min}$ \\
Interval between start & $30 \mathrm{~min}$ & $15 \mathrm{~min}$ \\
$\quad$ & & \\
\hline
\end{tabular}

estimated displacement velocity and the mass are likely to be reliable. Additional filtering includes the discarding of targets whose trajectories transit the outer edge of the radar beam (i.e. further than 0.85 half-power beam widths from the central axis) and the removal of any radar 'chaff' (ejected by the military), the fibres of which are distinguishable by the high ratio of their principal scattering cross-section terms $\left(\sigma_{\mathrm{xx}} / \sigma_{\mathrm{yy}}\right)$ (J.W. Chapman et al., unpublished). The resulting selection of targets (with correlation coefficients $>0.9$, etc) are designated as 'good' (Smith et al., 2000; Chapman et al., 2002a), and for these it is practicable to calculate the sensed volume for individuals of given mass, and thus to convert target numbers to aerial densities (Chapman et al., 2002a). In the present report, aerial density values are all expressed as the number of insects per $10^{7} \mathrm{cu}$. m. Targets with a correlation coefficient $\leqslant 0.9$ fit the analysis model less well, and are correspondingly classified as 'less good' or 'poor' (Chapman et al., 2002a). In dry weather (when there will be no interference from precipitation) low correlation coefficients are mainly caused by the presence of more than one insect within the sensed volume at the same time, i.e. interference between insect targets.

Apart from procedures designed to resolve separate insect targets, the analysis program also records routinely the percentage of time the received signal power is above each of ten power (threshold) levels, separated by $10 \mathrm{~dB}$ and starting at $-90 \mathrm{dBm}\left(10^{-12}\right.$ Watts $)$ which corresponds approximately to the noise level of the radar receiver. These 'percentage above threshold' values are useful because they provide some measure of the biomass of insects aloft in situations where aerial densities are too high for individuals to be resolved by the VLR. The percentage above threshold figures presented in this paper refer exclusively to those taken from the $-80 \mathrm{dBm}$ level only, and must be interpreted with care because high densities of small insects can be difficult to distinguish from precipitation, and even very scanty rainfall (hardly detectable at the ground) would interfere with this measurement. In practice, a stage in the layer analysis procedure (see below) was introduced to detect occasions when high 'percentage above threshold' values indicate rain.

It will be clear from the above that there are several ways of using VLR-derived data to characterize the vertical distribution of insects in the air, e.g. the numbers of 'all resolvable targets', the aerial density of 'good' targets, and the percentage above threshold values. Ideally, a significant layering feature will manifest itself in the vertical profiles of each of these variables, and caution is necessary if this does not occur. For example, during a few exceptionally warm evenings, insect densities in the layers were sometimes so great that it was difficult to resolve individual insects, and measurements of 'good' target numbers against height were unreliable in the first half of the night (see Results). 
In these situations, the percentage above threshold values may produce a truer picture of the insect height/density profile.

It should be noted that the range of detection of a target on the VLR is dependent on its mass (Chapman et al., 2002a, 2003), and care is needed to avoid the possible distortion of vertical distributions of insects due to the reduction in radar sensitivity to small targets at higher altitudes. Additionally, a decrease in the detection efficiency of small (but theoretically detectable) targets might be expected simply because small insects are much more common high in the air than are large ones (Chapman et al., 2004) and thus there is a greater likelihood of two or more small targets being in the sensed volume simultaneously, leading to inter-target interference. There is some empirical evidence that, in the aerial environment studied by us, some fall-off in detection efficiency might occur below $\sim 8 \mathrm{mg}$ (see fig. 4 in Smith et al., 2000). All things considered, the quantitative analysis of some occasions with apparently interesting vertical profiles may be problematic because a substantial percentage of targets may have low correlation coefficients (because of mutual interference or some other reason) and hence it will be difficult to acquire the reliable data on target mass needed for the calculation of aerial densities.

\section{Searching the VLR database for insect layers}

Examining each sampling period (every 15 minutes, 24 hours a day) manually for evidence of significant layering in the vertical profile of insect numbers would be very laborious, and so a Visual Basic module was developed to search the data held in a Microsoft Access database and return a 'Layer Quality' (LQ) code (a number between 0 and 7) indicating the layering status of each profile. Tables of these codes can then be examined for, say, a month at a time, and particular periods of interest (e.g. evenings with a string of high-significance code numbers for consecutive radar sample periods) then become apparent. The development of the insect layers can subsequently be studied in detail for particular periods by displaying the vertical profiles (of both target numbers and 'above threshold' data) themselves, usually by means of a sequence of graphs in Microsoft Excel. The Layer Quality processing module was designed to select layers which would have been picked out by someone experienced in examining this type of radar data, and in this sense it forms a simple 'expert system': the module operating procedures are outlined in appendix 1.

\section{Meteorological data}

Standard surface meteorological measurements were available at Rothamsted and Malvern, but for upper air data we had to rely on the operational radiosonde stations in the UK synoptic network, including army range stations such as Larkhill (fig. 1). For the present study, the most relevant data was that for midnight or $0600 \mathrm{~h} \mathrm{GMT}$. Some of the historical upper-air data were acquired from a very useful University of Wyoming website (http://weather.uwyo.edu/upperair/ sounding.html). In addition, since August 2000, hourly predictions have been made of meteorological variables in the air columns over each of the radar sites, generated from the operational mesoscale version of the Meteorological Office's Unified Model (MetSim profiles) (Cullen et al., 1997; Dickinson, 1999).
All the times quoted in this paper are in Greenwich Mean Time (GMT), in contrast to some of our earlier reports (Smith et al., 2000) which used British Summer Time.

\section{Results}

\section{Seasonal and diel frequency of insect layering}

The incidence of layering (as determined by the layer analysis procedures-see Methods) in each radar sampling period through the 24-h cycle is shown in fig. 2, for each of the four seasons. It can be seen that layering was commonest in the three summer months (June, July and August), considerably less common in autumn and spring months, and virtually absent in winter.

Figure 2 also shows, particularly for the summer months, a distinct diel structure which reflects the main flight periodicities in airborne insects over southern UK (cf. fig. 6 in Smith et al., 2000 and fig. 5 in Chapman et al., 2002a). Generally, layers were least common late in the night, when target numbers on the radar were also low. In the summer months, there was a small peak in the frequency of layering (representing dawn layers) occurring between 0330 and $0500 \mathrm{~h}$, before a large increase from 0600 to about $0830 \mathrm{~h}$ as daytime layering developed. In the spring and autumn, the dawn layering peak was not evident, and the build-up in daytime layering took place later in the morning (e.g. between 0900 and $1030 \mathrm{~h}$ in autumn). Daytime layers were most common around mid-day or early afternoon, and they declined in frequency over the late afternoon and early evening. Finally, there was a pronounced peak representing layering around dusk and the early part of the night.

\section{Identifying occasions with nocturnal layering by means of the Layer Quality analysis}

In the remainder of this report the focus is on nocturnal layering, and the analysis of the more numerous and complex daytime layers is deferred until later papers. Examination of the Layer Quality (LQ) monthly summary sheets revealed sequences of LQ scores of 4-7 which drew attention to the likelihood of layering on the nights in question. For example, the Layer Quality summary for the second half of August 2000 at Malvern suggested good layering on 20-21, 22-23, 24-25 and 29-30 August. Inspection of the actual vertical profiles of insect numbers confirmed that well-defined layers did indeed persist for extended periods on these nights, particularly when the Layer Quality summary contained a number of consecutive $\mathrm{LQ}=6$ values.

A fairly typical example of good night-time layering is provided by events on the night of 24-25 August 2000 at Malvern. Layering was present in the late afternoon, centred mainly about a height of $400 \mathrm{~m}$, and this persisted until after $1900 \mathrm{~h}$ GMT but had disappeared by $1930 \mathrm{~h}$. At that time there was a high concentration of insects in the lowest rangegates (fig. 3a), particularly in gate 1 which samples at a height of $150-195 \mathrm{~m}$ above ground level (agl). This lowaltitude concentration, presumably representing dusk takeoff (the end of civil twilight was at $1950 \mathrm{~h}$ ), continued until $2115 \mathrm{~h}$, but with a steepening profile, i.e. with comparatively more targets at higher altitudes. By $2130 \mathrm{~h}$, a distinct layer had developed (fig. $3 b$ ) with the density maximum in gates 2-3 (250-300 m), and this lasted until after $2315 \mathrm{~h}$ with the 

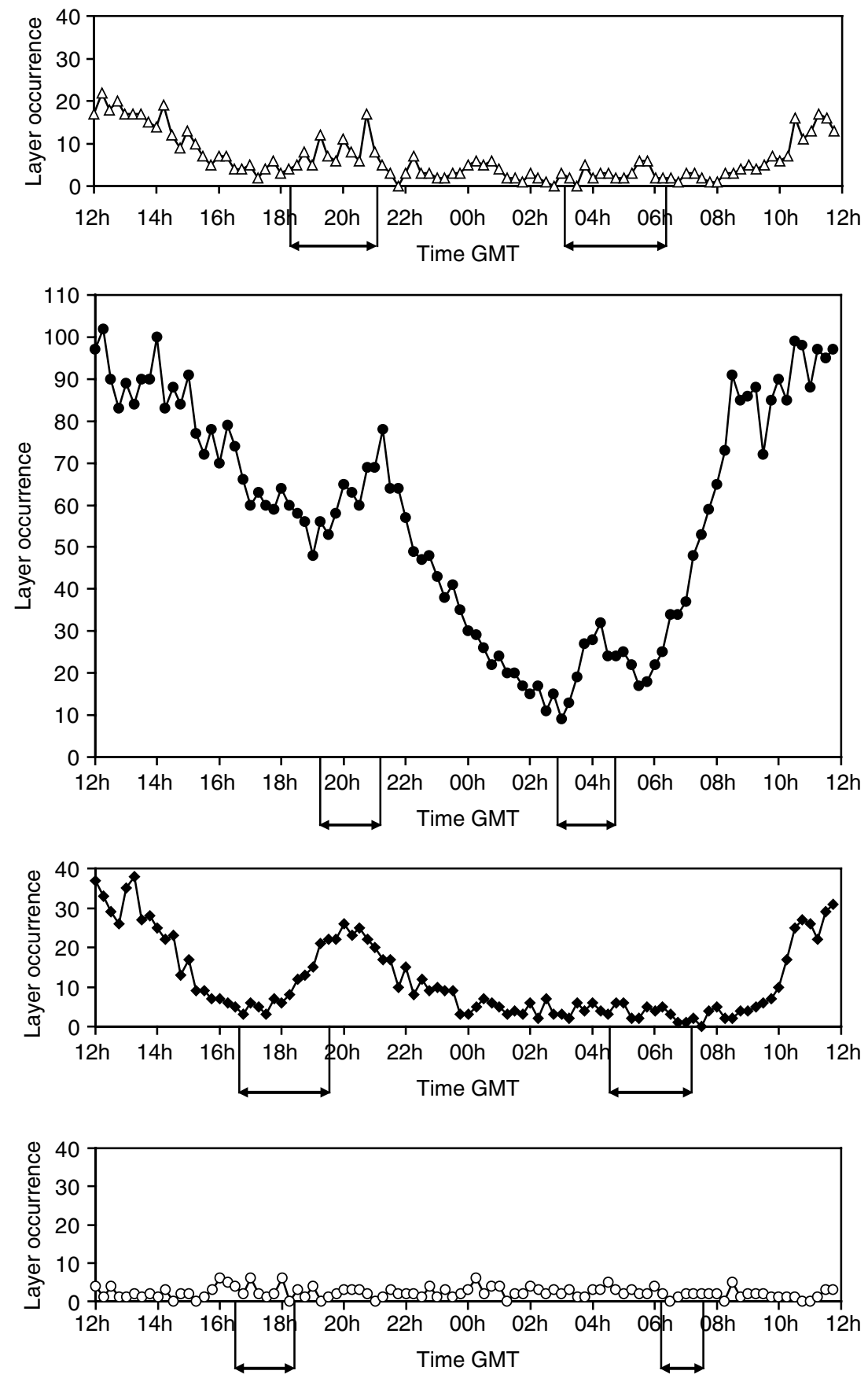

Fig. 2. Counts of the occurrence of an insect layer with a 'Layer Quality' value of 4, 5 or 6 (see Methods) for each 15 min period during the day/night. Graphs show the cumulative data for both sites (Malvern and Rothamsted) over two years (2000 and 2001). Data for the summer (i.e. June, July, August) $(\bullet)$, autumn $(\bullet)$, winter $(\bigcirc)$ and spring $(\triangle)$ are presented separately. Also shown on the 'Time' axis of each graph is the maximum extent of Civil Twilight (i.e. the earliest beginning and the latest end of Civil Twilight during each three-month period, considering both years and both sites).

maximum densities at $\sim 350 \mathrm{~m}$ (fig. 3c). By midnight, however, the single well-defined layer had collapsed and a double structure was apparent (fig. 3d). In the second half of the night, insect numbers tended to decrease and the profile became rather ragged and unstable, without persistent features, and between 0300 and $0400 \mathrm{~h}$ there were few insects flying at any height. Dawn flight activity started at $0430 \mathrm{~h}$ (civil twilight began about this time) with an increase in numbers in gate 1 . This reached a maximum at 0445 (fig. 3e), but declined by $0515 \mathrm{~h}$ (sun-rise was at 0510 ), and by $0545 \mathrm{~h}$ there were virtually no radar targets at any altitude (fig. 3f). It is interesting to note that the evolution of the profile of 

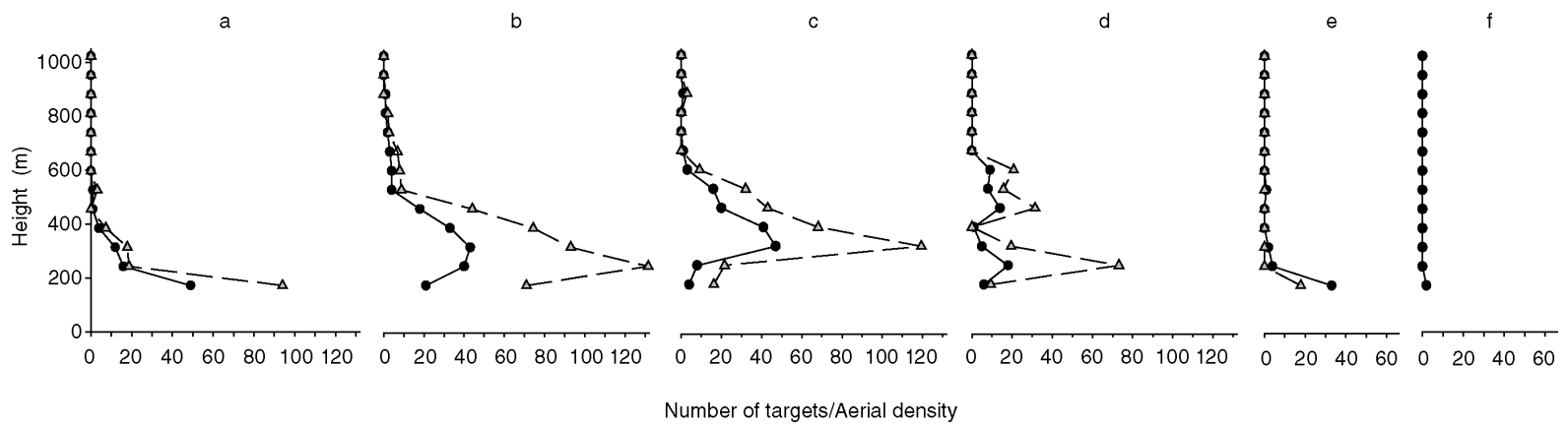

Fig. 3. Vertical distribution of insects as represented by number of targets ( $)$, and by aerial density (numbers per $10^{7} \mathrm{cu}$. $\mathrm{m}$.) $(\triangle)$, recorded by the vertical-looking radar at Malvern at (a) $1930 \mathrm{~h}$, (b) $2130 \mathrm{~h}$, (c) $2300 \mathrm{~h}$, (d) midnight, (e) $0445 \mathrm{~h}$ and (f) $0545 \mathrm{~h}$ during the night of 24-25 August 2000. Only targets which had estimated masses >12 mg (and which were detectable over all the heights shown) were used in the density calculations.

insect numbers shown in fig. 3 is similar to that documented in Drake's (1984) study in inland Australia-one of the few previous analyses of this topic.

In the above example, the layering events in the late afternoon or around sunset did not overlap with the layer forming after dark, but such temporal separation did not always occur. Generally speaking the night layers, even when well developed, tended to collapse between about midnight and $0200 \mathrm{~h}$ along with the general decline in insect numbers - the persistence of good layering all through the night until dawn was rare (but see the example from August 1995 described below). Where distinct dawn take-offs were evident (as on 25 August 2000), they did not commonly give rise to layers at radar-observable heights.

In contrast to nights with a number of consecutive $L Q=6$ values on the summary sheets, nights represented by scores of 5 or 4 indicated layering that was less pronounced and less persistent. For example, on 26-27 August 2000 at $2100 \mathrm{~h}$ there appeared to be a maximum in insect numbers at a height of about $650-700 \mathrm{~m}$ and perhaps the suggestion of another at about $380 \mathrm{~m}$, but an hour later there were, if anything, minima at the same heights. Moreover, these rather protean and complex changes in the vertical profile continued until shortly after midnight by which time insect numbers had declined. These poorly defined or more ephemeral layering events were considered to be far less suitable for investigation of the influence of physical factors than were the stable and persistent profiles seen, for example, on the night 24-25 August.

\section{'Saturation' of range-gates due to high insect densities}

If more than one target at a time is present within a rangegate, the returned signals will interfere to produce a poor fit to the analysis model and result in a low correlation coefficient (see Methods), or sometimes the analysis algorithm may not converge to a solution and so a signal 'fail' will be registered. If a high number of 'fails' occur, it would be possible for high-density layers to appear, misleadingly, as minima in the vertical profile of insect abundance. In order to avoid this situation, it is highly desirable to check that noteworthy features in the profile of insect numbers (or aerial densities) are reflected in the 'percentage above threshold' figures.
An example of range-gate 'saturation', due to particularly high insect densities, can be illustrated by some results from early August 1995. This was a record-breaking month, with the first three days being particularly hot (Weather Log for August 1995, in Weather magazine, Royal Meteorological Society). On the night of 1-2 August, a minimum temperature of $21^{\circ} \mathrm{C}$ was recorded at the Malvern radar site, and large numbers of insects were flying at altitude. A dense layer built up soon after sunset, and this persisted all night, albeit with reduced densities after about $0300-0400 \mathrm{~h}$. At $2130 \mathrm{~h}$, the profile of insect numbers appears to show a double layer with a minimum at $c .700 \mathrm{~m}$ agl (fig. 4a). In fact, it can be seen from the percentage above threshold values, which in this instance give a truer picture of the profile, that maximum numbers occurred at $650-700 \mathrm{~m}$, but insect densities were too great for the analysis procedure to resolve individual targets. By $0100 \mathrm{~h}$, the layer was centred at a much lower altitude (about $300 \mathrm{~m}$, see fig. 4c), but there still appeared to be a slight depression of the peak in the numbers profile. Finally, by $0300 \mathrm{~h}$ densities had decreased to the extent that the peaks in target numbers and in the percentage above threshold values were now in accordance (fig. $4 \mathrm{~d}$ ).

Inspection of the vertical profiles for several very warm nights at the beginning of August 1995 indicated that a high percentage of signal 'fails' occurred when target counts in individual gates reached $\sim 60$ per $5 \mathrm{~min}$ sampling period, although this will be dependent on wind speed and target mass. Fortunately for the present study, aerial densities were rarely high enough at night for this saturation effect to occur, although it may be more of a problem when considering daytime VLR profiles during hot summer weather.

\section{The seasonal incidence of 'good' nocturnal layering}

Reference has been made above to certain nights in the summers of 1995 and 2000 when well-defined insect layers persisted for at least $2-3 \mathrm{~h}$ during the night (as revealed by a sequence of high scores from the layer quality analysis). The question then arises as to the seasonal incidence of welldeveloped night-time layers, and further examination of the Layer Quality data (for the four years between 1999 to 2002) showed that they only occurred during the months of June, July and August, and in some years, in early September. Even in the summer months, however, occurrence was 

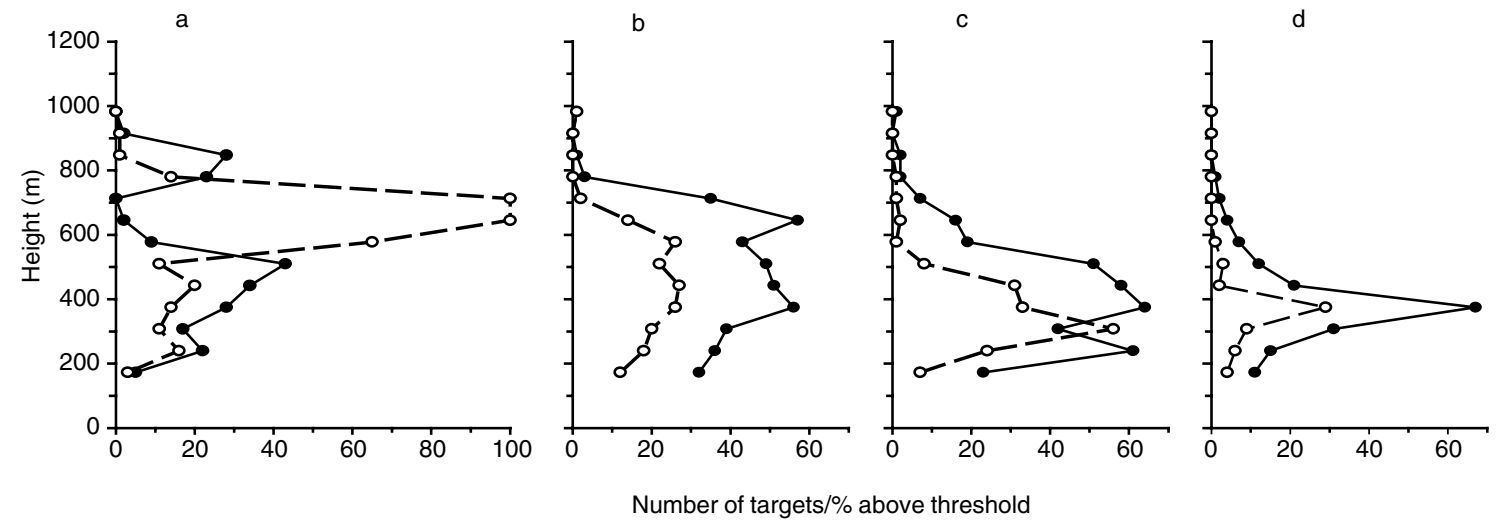

Fig. 4. Vertical distribution of insects as represented by numbers of targets $(\mathbf{O})$ and by 'percentage above threshold' values $(\bigcirc)$ (see Methods), recorded by the Malvern radar at (a) $2130 \mathrm{~h}$, (b) $2330 \mathrm{~h}$, (c) $0130 \mathrm{~h}$ and (d) $0300 \mathrm{~h}$ during the night of 1-2 August 1995.

variable with some months, e.g. August 2000 at Malvern, having half a dozen nights with 'good' layers, while July 2000 at the same site had none. The impression gained was that strong night-time layering was generally associated with fine, hot weather during the preceding day, followed by clear night skies leading to a temperature inversion, but without night-time temperatures falling below values needed to initiate and maintain migratory flight.

\section{Relationships between the vertical distribution of insects and meteorological factors}

In this section, the association between selected instances of nocturnal insect layering and atmospheric variables is examined, with particular reference to air temperature profiles measured by radiosonde ascents at various upperair stations in southern UK. Information from the MetSim profiles generated for the radar sites themselves is also considered, although it must be borne in mind that these simulations may not be representative of the real profiles in every detail.

\section{1-2 August 1995}

At the end of July and beginning of August 1995, Britain experienced sunny and exceptionally hot weather, under the influence of high pressure over Scandinavia and a warm easterly airflow over the country. On the evening of 1 August, as mentioned above, the radar at Malvern recorded intense insect layering which continued all through the night. Not surprisingly, radio-soundings made at $0000 \mathrm{~h}$ on 2 August at several upper air stations in southern UK (Camborne, Aughton, Herstmonceux, fig. 5b) revealed temperature inversions due to radiative cooling from the surface and furthermore, temperatures at the top of the inversions (at c. $300 \mathrm{~m}$ agl) were very warm $\left(25-27^{\circ} \mathrm{C}\right.$ ) for the time of night. This extensive layer of warm air corresponds with the presence and position (centred just above $300 \mathrm{~m}$ agl) of the strong insect layer detected by the radar at $0030 \mathrm{~h}$ (fig. 5a).
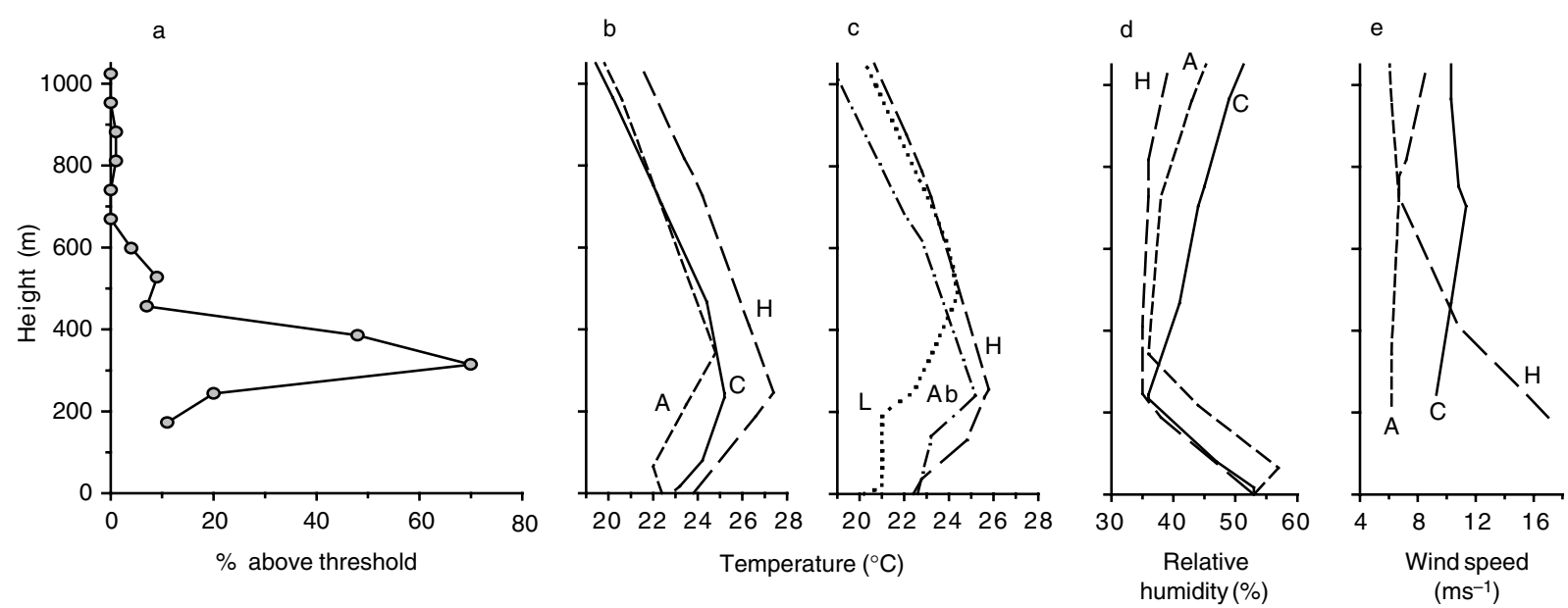

Fig. 5. Vertical profiles of insects and meteorological variables for the night of 1-2 August 1995: (a) 'percentage above threshold' values derived from Malvern radar data recorded at $0030 \mathrm{~h}$; (b) air temperatures at Camborne (C), Aughton (A) and Herstmonceux (H) at midnight; (c) air temperatures at Aberporth ( $\mathrm{Ab}$ ), Larkhill $(\mathrm{L})$ and Herstmonceux $(\mathrm{H})$ at $0600 \mathrm{~h}$; $(\mathrm{d}$ and e) relative humidity and wind speeds at Herstmonceux, Camborne and Aughton at midnight. 
a

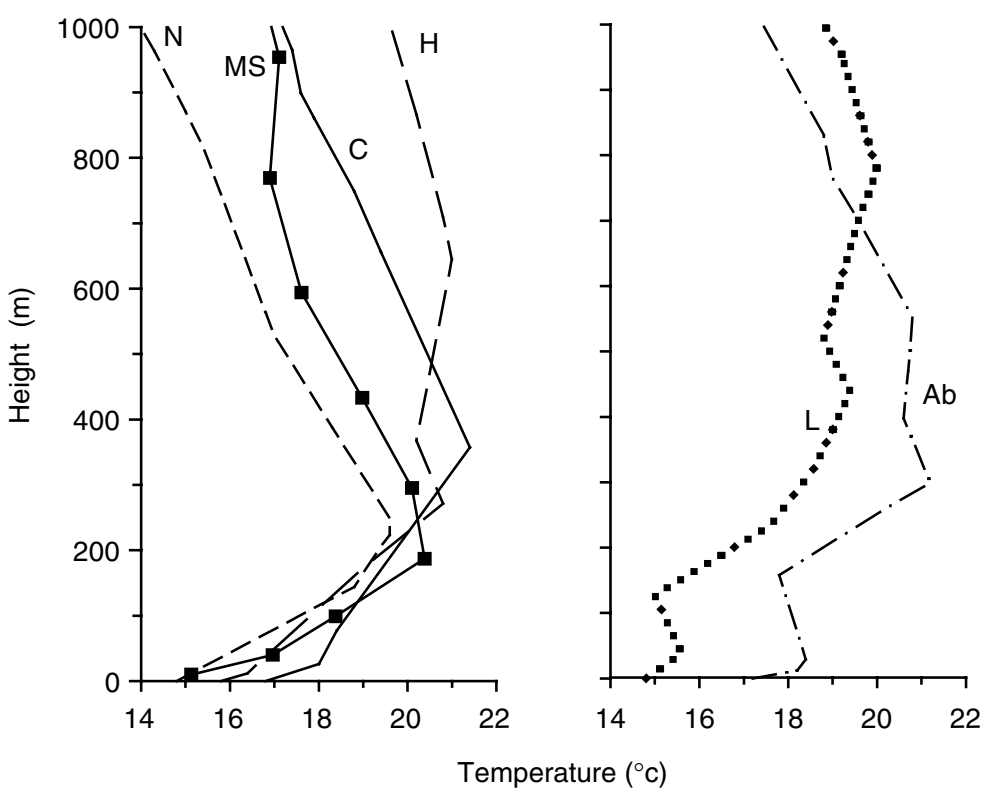

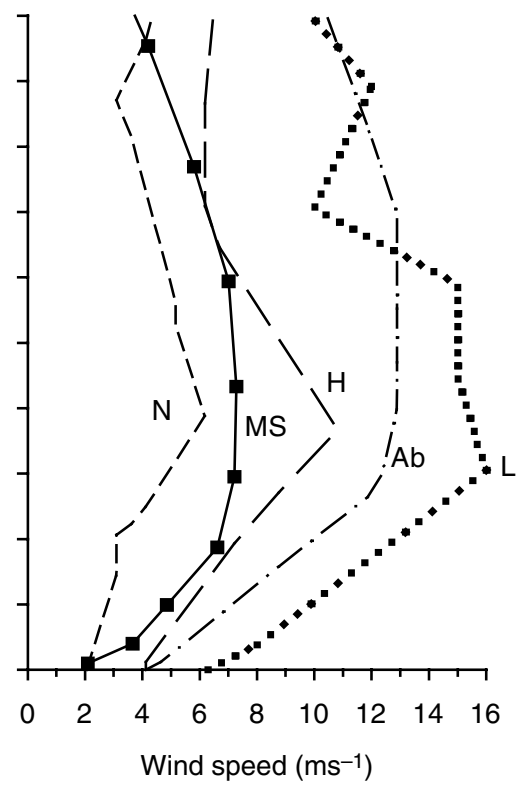

Fig. 6. Vertical profiles of meteorological variables for the night of 24-25 August 2000: (a) air temperatures at Camborne (C), Nottingham (N) and Herstmonceux (H), and the MetSim temperatures for Malvern (MS) at midnight; (b) air temperatures at Aberporth and Larkhill at $0600 \mathrm{~h}$; (c) wind speeds at Nottingham and Herstmonceux (and the MetSim wind speeds for Malvern (MS)) at midnight, and wind speeds at Aberporth and Larkhill at $0600 \mathrm{~h}$.

The inversion was still strongly developed at $0600 \mathrm{~h}$ the next morning (see Larkhill temperature profile, fig. $5 \mathrm{c}$ ) and this may account for a weak insect layer which was detected at $c$. $450 \mathrm{~m}$ at that time.

The question arises as to whether the insects in the layers were responding to the air temperature itself, or to some other meteorological variable associated with the inversion, for example, relative humidity or wind velocity. In the present case (see fig. $5 \mathrm{~d}$ and e) these variables did not consistently show changes (namely decreases in wind speed, increases in humidity) which would account for the rapid decline in insect abundance above the inversion. So, on balance, the insect distribution seemed more consistently associated with the temperature profile than with the profiles of humidity or wind speed.

\section{August 2000 case studies}

As mentioned above, there were several occasions with good nocturnal layering in the second half of August 2000, particularly at the Malvern site. The relationship between layers and meteorological factors on three of these nights, namely 22-23, 24-25 and 29-30 August, is examined here.

22-23 August. After the disturbances (widespread thunder and hail) on the previous day, the 22 August was a quiet day (Weather Log for August 2000, in Weather magazine, Royal Meteorological Society; Roger Brugge's Weather Diary, http://www.met.rdg.ac.uk/ brugge/). High pressure was developing over the country, and many areas of central, southern and south-eastern England were dry and sunny. However, a southward-moving depression was still affecting the southwest, producing cool conditions and rain in Cornwall. On the night of 22-23 August, the upper air stations showed easterly winds at insect flight heights, and temperatures remained rather low (e.g. a maximum of $16^{\circ} \mathrm{C}$ at $300-400 \mathrm{~m}$ agl recorded by the Herstmonceux sonde at midnight). Several of the stations showed no night-time surface inversion, but the inland stations closest to the Malvern site, namely Larkhill and Herstmonceux, did show an inversion with the warmest temperatures and strongest wind speeds (up to $14 \mathrm{~m} \mathrm{~s}^{-1}$ ) at about $300-400 \mathrm{~m}$, as did the midnight MetSim profiles of temperature and wind-speed for the Malvern site. This may explain the pronounced insect layer occurring at this altitude between 2030 and $0130 \mathrm{~h}$ on the night in question (see fig. 6 in Chapman et al., 2003).

24-25 August. On 24 August, high pressure over the UK ensured a fine warm day in central southern, south-eastern and midlands areas of England. The night of 24-25 August was warmer than the night of $22-23$ (e.g. maxima of $21^{\circ} \mathrm{C}$ were recorded at 270 and at $640 \mathrm{~m}$ agl for Herstmonceux at midnight) but winds at insect flight heights were still from the east. The vertical distribution of insects at Malvern on this night has already been described in detail, and attention was drawn to a layer at about $250-300 \mathrm{~m}$ agl which lasted from $2130 \mathrm{~h}$ until almost midnight. Examination of upper air data for $0000 \mathrm{~h}$ on 25 August revealed that temperature inversions were widespread. Sometimes these had a simple structure with the inversion top at a similar height to the layer (e.g. at Camborne and Nottingham at midnight; note also the MetSim temperature analysis for Malvern at midnight) (fig. 6a), but at other stations the temperature profiles had a more complex form with a double maximum (Herstmonceux at midnight for example, as mentioned above, and also Larkhill at $0600 \mathrm{~h}$ (see fig. 6b)). It is likely that 

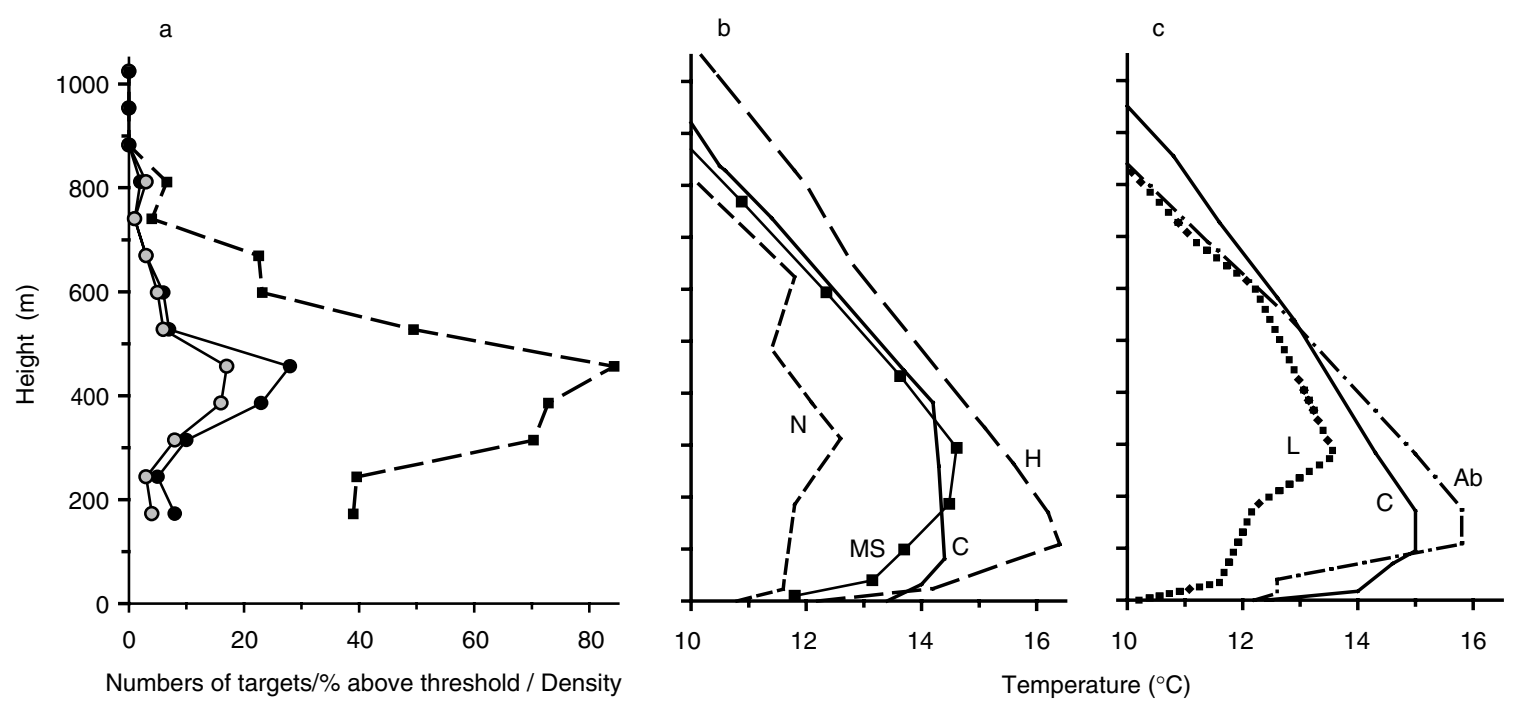

Fig. 7. Vertical distribution of insects and temperature for the night of 29-30 August 2000: (a) number of insects (O), density of insects (numbers per $10^{7}$ cu.m) $(\boldsymbol{\square})$ and 'percentage above threshold' values $(\mathrm{O})$ derived from Malvern radar data recorded at midnight; (b) air temperatures at Camborne (C), Nottingham (N) and Herstmonceux (H), and the MetSim temperatures for Malvern (MS) at midnight; (c) air temperatures at Camborne (C), Larkhill (L) and Aberporth (Ab) at $0600 \mathrm{~h}$.

the insect layer at Malvern in the hours before midnight was due to the simpler temperature profile, and the breakdown of this layer around midnight (see fig. 3d) was caused by the establishment of a more complex temperature regime. The Malvern MetSim profile certainly evolved after midnight, with the temperature maximum at $\sim 300 \mathrm{~m}$ tending to become less pronounced, and temperatures becoming more isothermal above this height.

Wind speed profiles for the upper air stations on 24-25 August showed maxima at heights similar to the insect layer, or slightly above (fig. 6c). Distinguishing the influence of temperature from that of wind speed on the migrants was not straightforward on this night.

29-30 August. The 29 August was a quiet day after several days of showery weather, and there was some sunshine in the south and parts of the west of England. Night-time temperatures were not particularly warm (e.g. maximum of $16.4^{\circ} \mathrm{C}$ at $109 \mathrm{~m}$ agl at Herstmonceux at $0000 \mathrm{~h}$ on 30 August), and winds at flight heights were again easterly. An insect layer was observed with the Malvern radar from $2115 \mathrm{~h}$ onwards, with maximum numbers between about 240 and $380 \mathrm{~m}$ agl early in the night, but at a slightly higher altitude $(380-450 \mathrm{~m}$ agl) around midnight (fig. 7a). The layer became unstable after about $0030 \mathrm{~h}$ and insect numbers then declined at all altitudes.

The midnight and $0600 \mathrm{~h}$ radio-soundings on 30 August revealed strong surface inversions, but the warmest air (top of the inversion) occurred at a rather low altitude at several of the stations (e.g. c. $100 \mathrm{~m}$ agl at Herstmonceux at midnight, and at Aberporth at $0600 \mathrm{~h}$ ) (fig. 7b, c), which did not correspond well with the altitude of the insect layer observed at Malvern (c. 300 to $400 \mathrm{~m}$ agl). At some inland sites, however, the warmest air did occur at higher altitudes (e.g. at about $300 \mathrm{~m}$ at Nottingham at midnight and Larkhill at 0600h, and in the MetSim analysis for Malvern at midnight) so it is possible that the altitude of the insect layer could be explained by a maximum in the air temperature profile. Wind-speed profiles from the upper-air stations were also examined, but maxima occurred at a wide variety of altitudes and they did not accord with the insect profiles in any very consistent manner on this night.

\section{Double layers-June 2000 case studies}

It may be argued that there is only a limited altitude band where both a nocturnal insect layer and a maximum in the air temperature profile (particularly one due to radiative cooling) are likely to occur, and consequently any correspondence between the two may be due to chance. Consideration was therefore given to some occasions when well-developed double layers of insects were recorded, to observe how this more complex vertical distribution was associated with the temperature profile.

The nights of 17 to 19 June 2000 were some of the warmest of the year at the radar sites, following hot sunny days. Nocturnal insect layers developed during these nights, and the insect vertical distribution often showed a quite persistent double structure, in contrast to the single layers described above. On the night of 17-18 June 2000, for example, two layers were present at Malvern from c. 2115 to $0045 \mathrm{~h}$. The more intense lower layer was centred at about 300 or $400 \mathrm{~m}$ agl and the upper one at about $800-900 \mathrm{~m}$ (fig. 8a). The layering broke down after $0100 \mathrm{~h}$, and the dawn increase in the lowest range-gate was evident at $0245 \mathrm{~h}$. At the Rothamsted site, the layers were less developed and persistent, perhaps because air temperatures were lower here than at Malvern $\left(14.0^{\circ} \mathrm{C}\right.$ at the surface at midnight as opposed to $18.4^{\circ} \mathrm{C}$ ). There was, however, evidence of a lower layer at $300 \mathrm{~m}$ between 2230 and $0030 \mathrm{~h}$, and a short-lived upper one at $850 \mathrm{~m}$ between 2245 and $2315 \mathrm{~h}$.

On 17 June 2000, there was high pressure to the east of the UK, resulting in a warm southerly airflow, at least over the south of England. Radio-soundings at midnight at Camborne, RAF Woodvale and Herstmonceux, as well as 


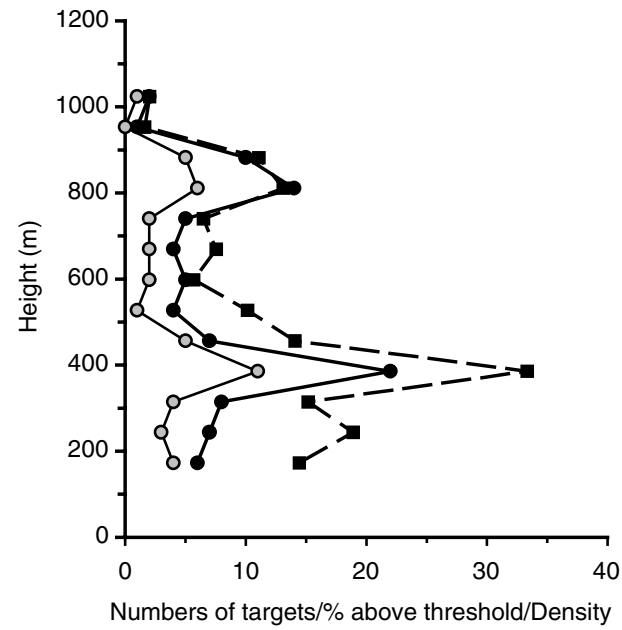

b

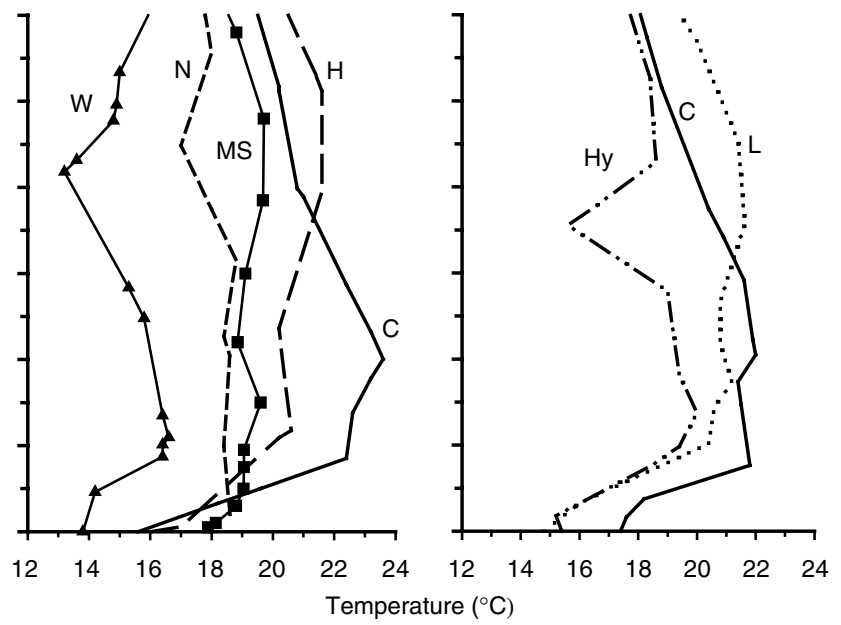

Fig. 8. Vertical distribution of insects and temperature for the night of 17-18 June 2000: (a) number of insects (-), density of insects (nos. per $\left.10^{7} \mathrm{cu} . \mathrm{m}\right)(\boldsymbol{\square})$ and 'percentage above threshold' values (O) derived from Malvern radar data recorded at $2345 \mathrm{~h}$; (b) air temperatures at Camborne $(\mathrm{C})$, Woodvale $(\mathrm{W})$, Nottingham $(\mathrm{N})$ and Herstmonceux $(\mathrm{H})$, and the MetSim temperatures for Malvern (MS) at midnight; (c) air temperatures at Camborne (C), Larkhill (L) and Hemsby (Hy) at $0600 \mathrm{~h}$.

soundings at $0600 \mathrm{~h}$ at Larkhill and Hemsby (fig. 8b, c), all showed a surface temperature inversion, the top of which lay between $200 \mathrm{~m}$ and $400 \mathrm{~m}$. (Nottingham at midnight, however, showed a layer with a fairly constant temperature (isothermal) up to $600 \mathrm{~m}$.) Warm air (temperatures of $\sim 20^{\circ} \mathrm{C}$ ) at the top of this inversion presumably accounted for the lower of the two insect layers detected by the radars. There was also widespread evidence of a higher altitude inversion (perhaps a capping inversion left from the daytime atmospheric boundary layer) with local maxima in temperature at heights of $800-1100 \mathrm{~m}$ (fig. $8 \mathrm{~b}, \mathrm{c}$ ). This would be consistent with the presence of the upper insect layer around $800-850 \mathrm{~m}$ observed on this night.

The 18-19 June 2000 was the warmest night of the period, and the upper air stations in southern UK were recording temperatures of at least $21^{\circ} \mathrm{C}$ at midnight at insect migration heights. Considerable numbers of insects were engaged in migratory flight, but the height-density profiles seemed rather labile, without stable layers persisting at particular heights. This may have been because very favourable temperatures prevailed over a wide range of insect flight heights on this night.

On the night of 19-20 June, two layers of insects were present at Rothamsted from about $2130 \mathrm{~h}$ (fig. 9b). The strong lower layer was centred at $400-500 \mathrm{~m}$ above ground and was discernible until about $0300 \mathrm{~h}$. The upper layer was located at $800 \mathrm{~m}$ or higher, and this disappeared after $0030 \mathrm{~h}$. At the Malvern site, the upper layer was the more pronounced of the two and again, it was usually situated at about $800-900 \mathrm{~m}$ agl (fig. 9a). It persisted until $0115 \mathrm{~h}$. The lower layer was generally less well-developed at Malvern than at Rothamsted, and it had declined by $2330 \mathrm{~h}$.

Radio-soundings at $0000 \mathrm{~h}$ on 20 June at Camborne, RAF Woodvale and Nottingham, as well as $0600 \mathrm{~h}$ at Larkhill
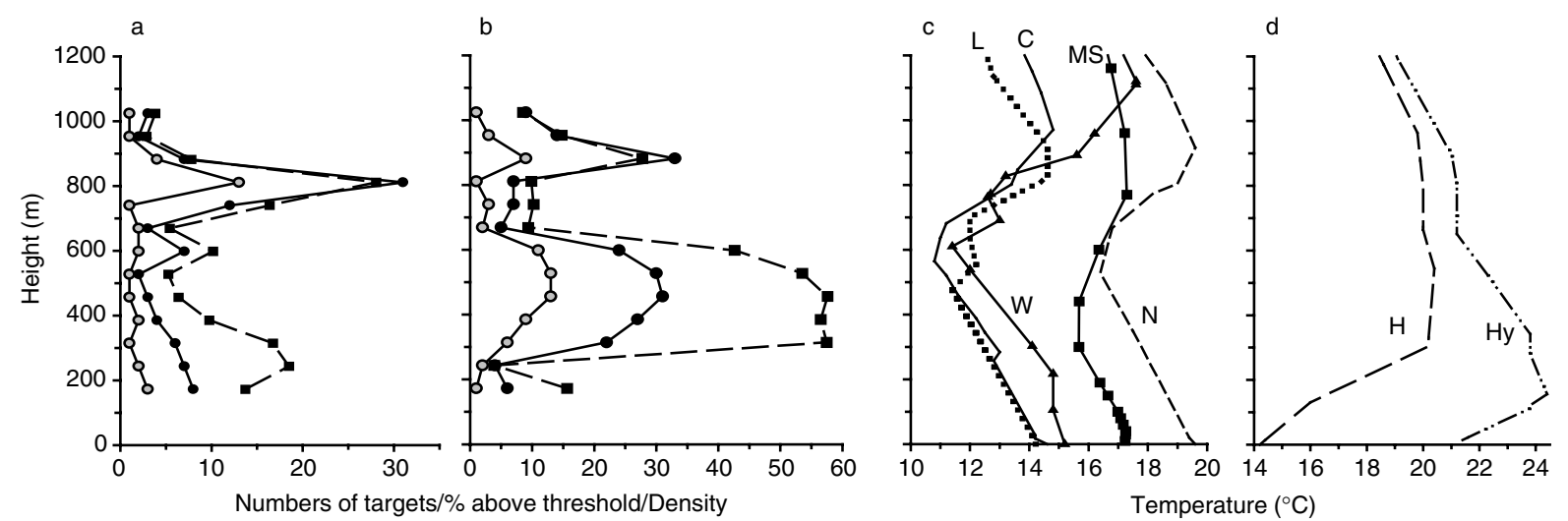

Fig. 9. Vertical distribution of insects and temperature for the night of 19-20 June 2000. Numbers of insects (-), density of insects (nos. per $\left.10^{7} \mathrm{cu} . \mathrm{m}\right)(\boldsymbol{\square})$ and 'percentage above threshold' values (O) derived from data recorded by the radar at (a) Malvern (midnight) and (b) Rothamsted $(2330 \mathrm{~h})$. (c) Air temperatures at Camborne (C), Woodvale (W), Nottingham (N) at midnight, Larkhill (L) at $0600 \mathrm{~h}$, and the MetSim temperatures for Malvern (MS) at 2300 h. (d) Air temperatures at Herstmonceux (H) and Hemsby (Hy) at midnight. 
(fig. 9c), all show weakly unstable air near the surface with dropping temperatures, and above this a strong deep inversion. At Nottingham, for example, inversion temperatures increased from $16.8^{\circ} \mathrm{C}$ at about $670 \mathrm{~m}$ above ground to $19.6^{\circ} \mathrm{C}$ at $920 \mathrm{~m}$. It seems very probable that the upper insect layer detected by the radars was associated with this capping inversion. The most easterly stations (Herstmonceux, Hemsby) (fig. 9d), however, showed a strong surface inversion at midnight, but an isothermal layer replaced the higher altitude inversion. This may account for the fact that at Rothamsted (the more easterly of the radar sites) the lower insect layer was stronger than the upper one, and that it was still well developed at midnight, in contrast to the situation at Malvern where the lower layer had declined by this time.

\section{Aggregated density-height profiles}

Figure 10 shows the distribution of mean insect density with height for the night-time in the summer months (June/ July/August) of 2000, considering only targets of mass $\geqslant 10 \mathrm{mg}$, which can be detected by the VLR up to about $930 \mathrm{~m}$. The profile for July exhibits a monotonic decrease in density with height, of a semi-logarithmic type. In contrast, the August profile (and to a lesser extent, the June profile) shows apparent evidence of stratification, with a maximum in range-gate 2 (about $240 \mathrm{~m}$ above ground) and a reversed trend below this height. However, calculation of the mean 'percentage above threshold' values for the lowest gates in August again reveals a decrease of density with height (fig. 10). Therefore, the apparently lower average densities in range-gate 1 are most likely to be an artefact caused by the large number of targets 'saturating' this gate. The indications are thus that the overall vertical distribution of radar-detectable insects at night is less influenced by rather spectacular nights with distinct and stable layers than by the more frequent nights without well-marked layering.

\section{The size distribution of insects in the layers}

Consideration of the insect size (i.e. mass) distributions for all the layering occasions described here is beyond the

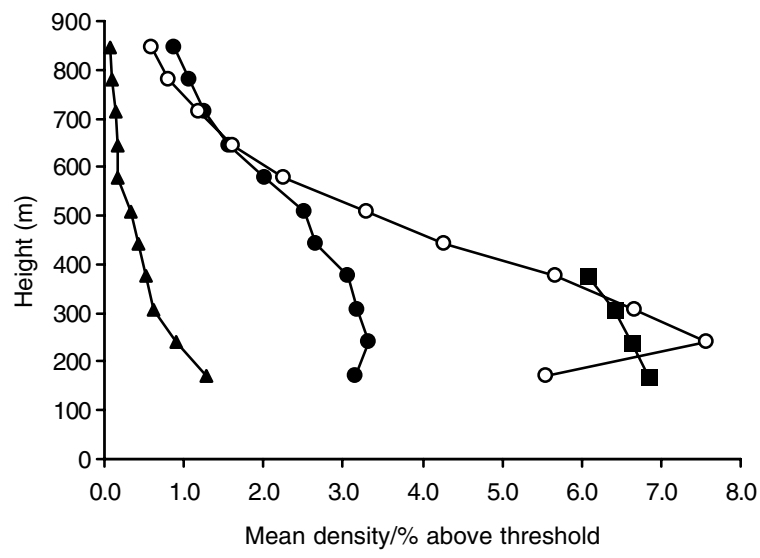

Fig. 10. Vertical distribution of night-flying insects (of mass $>10 \mathrm{mg}$ ) detected by the Malvern radar in summer 2000. Mean density profiles are shown for June $(\boldsymbol{\bullet})$, July $(\mathbf{\Lambda})$ and August $(\bigcirc)$, and 'percentage above threshold' values for August $(\boldsymbol{\square})$. scope of this paper, and only two illustrative examples will be presented. When producing these mass distributions, only individuals large enough to be detectable at the altitude range occupied by the layer in question have been included in the analysis (for example, an insect would have to weigh $\geqslant 10 \mathrm{mg}$ to be detected in a layer at a height of $\sim 1 \mathrm{~km}$ ).

The first mass distribution example is taken from the insects forming the double layer observed at Malvern on 17-18 June 2000. On this night, the lower layer was composed of species in a large range of mass categories, with little sign of a dominant taxon (fig. 11). Masses in the upper layer, on the other hand, showed a well-marked peak between 100 and $140 \mathrm{mg}$, which corresponds to the mass of medium-sized noctuid moths. Examination of moth catches from the nearest Rothamsted Insect Survey (RIS) light-trap to the Malvern VLR, i.e. Bredon Hill, Worcestershire showed that among noctuids present during 16-20 June were Mythimna pallens Linnaeus (the common wainscot) and Agrotis exclamationis Linnaeus (the heart and dart) both of which may engage in migratory flight as records from Shetland show (http://www.wildlife.shetland.co.uk/ insects/moths.htm, http://www.nature.shetland.co.uk/old news/2000insectarch.html). In addition, there were two specimens of Autographa gamma Linnaeus (Noctuidae) (the silver-Y), as well as 54 Plutella xylostella (Linnaeus) (Yponomeutidae) (the diamondback moth), both well-known migrants. Plutella xylostella is too small to have been detectable individually in the layers, but its presence is indicative of a migration event (Chapman et al., 2002b). Examination of the annual pattern of catches of A. gamma (from all Rothamsted Insect Survey light-traps throughout 2000) showed clear evidence for an immigration of these moths in June, peaking on 18 June (I.P. Woiwod, unpublished data). The warm southerly airflow recorded during this period, and the rapid displacement of insects in the radar-detected layers, would be conducive to cross-Channel movements, although many of the insects in the layers would have originated from closer sources.

The second example is taken from the mass distribution of insects in the layer observed at a height of about $300 \mathrm{~m}$ around midnight on 22-23 August 2000 at Malvern. The layer contained insects of various sizes, but there was a peak at $120 \mathrm{mg}$ (fig. 12), which again corresponds to the mass of medium-sized noctuid moths. Examination of catches from the Rothamsted Insect Survey light-trap at Bredon Hill indicated that the commonest species of moth was the noctuid Xestia c-nigrum (Linnaeus) (the setaceous Hebrew character), which can be migratory in northern Europe (Palmqvist, 2000), and M. pallens and A. gamma were also caught.

It was clear from these and other examples that a variety of insects with a large range of masses (from a few up to several hundred milligrams) contributed to the layers detected by the VLRs, and this implies that the processes leading to layer formation may reflect a rather general behavioural reaction to the prevailing atmospheric conditions, manifested in a wide range of taxa.

\section{Discussion}

The deployment of fully-automated insect-monitoring radars in the UK (Smith et al., 2000; Chapman et al., 2003) and in Australia (Drake, 2002) has meant that tools are now available to undertake systematic, long-term studies of the vertical distribution of insects in the atmosphere (at least 


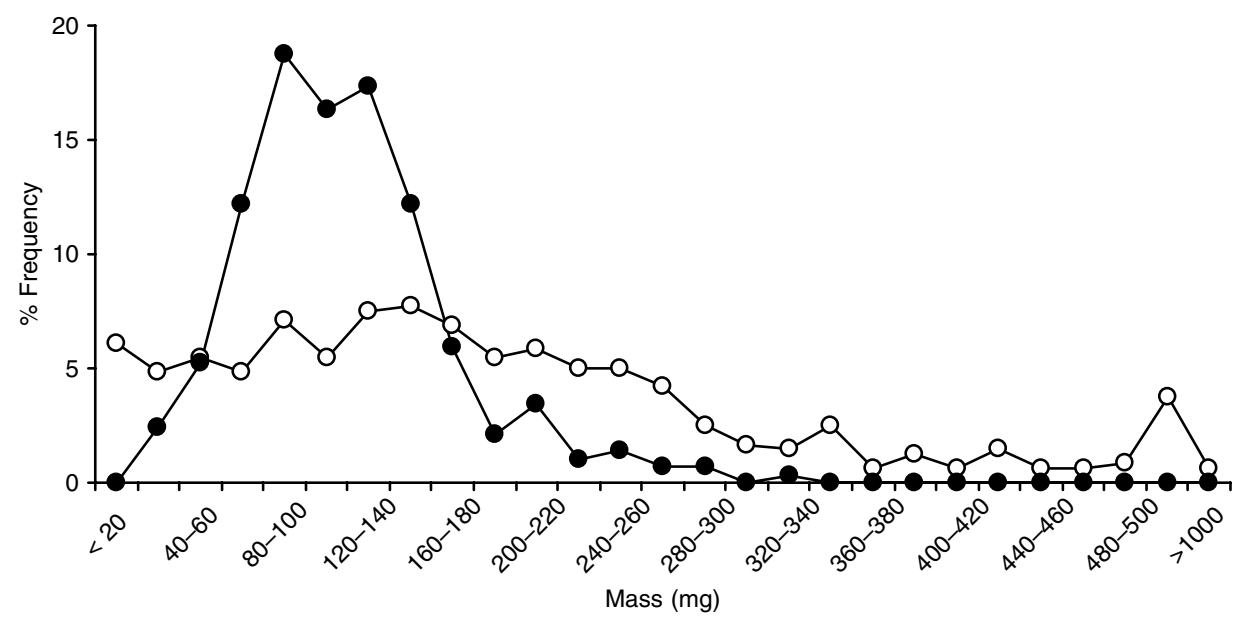

Fig. 11. Distribution of mass for insects forming the layers observed between $2116-0021 \mathrm{~h}$ on $17-18$ June 2000 at Malvern (cf. fig. 8). Open circles: insects in lower layer (range-gates $3-5$, c. $290-480 \mathrm{~m}$ above ground); these targets had masses $\geqslant 7 \mathrm{mg}, n=480$. Filled circles: insects in upper layer (gates 9-11, c. 720-905 m); all these targets had masses $>29 \mathrm{mg}, n=288$.

for the larger species) or, in other words, to develop a sort of 'climatology' of layering (Drake \& Rochester, 1994). This approach implies that statistical relationships derived from long sequences of insect vertical distribution data and accompanying physical variables will allow the estimation of the probability that particular migrations will occur at specific times and heights in the atmosphere (Drake \& Rochester, 1994). This goal is still some way off, but we have taken some steps towards it by devising an expert system to scan large amounts of accumulated radar data for the presence of insect layers which are well-defined, stable in altitude, and persistent over at least an hour or more. The probable influence of meteorological factors on certain types of layers has been considered here, albeit by employing a case-study approach rather than a statistical consideration of the whole data-set.

The present paper is largely concerned with insect layering after dark but as we have seen, layers also commonly occurred during the day (see example in Chapman et al., 2002a), around sunset, and occasionally at dawn. The day-time and crepuscular layers were sometimes temporally distinguishable from each other and from the true nocturnal layers, but on other occasions, particularly in very hot weather when vast numbers of insects were flying at altitude, the layering periods overlapped (e.g. in early August 1995). Layers occurring at different times of the day/night might be expected to have different causes: in some cases the insect's behaviour may be dominant (via an optomotor effect, for example), while in other cases meteorological factors may be strongly influential (see reference in the Introduction to the work of Ottersten (1970) and Campistron (1975)). The causes of the stratification in the day-flying insect profiles needs further investigation, but some of the insect layers occurring at high altitude in fine weather are apparently associated with a capping inversion - an elevated stable layer in the atmosphere that forms a 'lid' on a convective boundary layer, or with some other high-level inversion. The exact altitude of the insect density maximum in relation to an inversion (i.e. above or below it) may be influenced by the origins of the air-streams making up the wind profile, i.e. whether these air-streams have passed over regions harbouring stronger or weaker ground sources of migrants (Gossard \& Strauch, 1983).

The crepuscular layers observed on the vertical-looking radars are, at present, poorly understood. It seems likely that they are mainly composed of insects which make short migratory movements around sunset or sunrise, and which land soon after the end of the twilight. However, very occasionally a dawn layer has been observed to persist for several hours in the early morning (an example occurred on 17 June 2000 when a layer persisted at about $400 \mathrm{~m}$ from about $0330 \mathrm{~h}$ until at least $0630 \mathrm{~h}$ ). It is conceivable that some of the short-lived crepuscular layers may be formed by species engaged in non-migratory behaviour: we have seen stationary clouds of insects over landmarks at dawn (e.g. a swarm of Diptera over the VLR in Mali which extended up to several hundred metres above ground; J.R. Riley, 1978, unpublished observation).

The insects in the true nocturnal layers observed with the radars were plainly migrating. When layers occurred, they were often detected at similar altitudes at both radar sites. This, along with the persistence of the layers over several hours and the displacement speed of insects within them, leads to the conclusion that these are not local features but that they cover large areas of England on some nights. They are probably typical of inland sites in southern UK, and may well be characteristic of a wider area of north-western Europe.

Radar studies in very different environments in other parts of the world have shown that the vertical distribution of nocturnal migrants is frequently related to the stratification of temperature and wind shear within the atmospheric boundary layer (Drake \& Farrow, 1988; Gatehouse, 1997). Night-time layers are often associated with air temperature profiles, and this can be simply a matter of the insects flying in the warmest available air, often that at the top of a surface temperature inversion (Schaefer, 1976; Riley \& Reynolds, 1979; Drake, 1985; Drake \& Farrow, 1988). However, migrants could also accumulate because they are inhibited (at least for a time) from descending into colder air at lower altitudes under inversion conditions (Johnson, 1969). In practice, it might be difficult to distinguish between these 


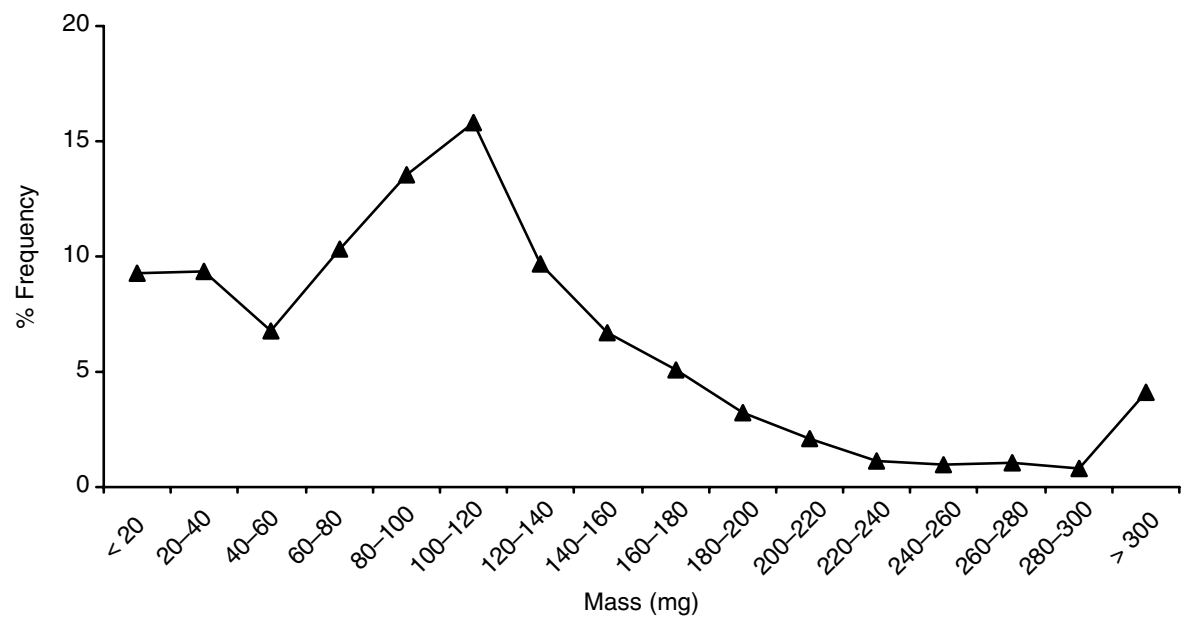

Fig. 12. Distribution of mass for insects forming a layer centred at a height of $300-400 \mathrm{~m}$ between 2045 and $0120 \mathrm{~h}$ on the night of the 22-23 August 2000 at Malvern. (All targets in the layer had masses $>5 \mathrm{mg} . n=1321$.)

two temperature effects. Density maxima occurring well above the altitude of the warmest air may be caused by insects ascending until they approach a ceiling above which temperatures are behaviourally or physiologically too cold for flight (ceiling layer) (Riley \& Reynolds, 1979; Riley et al., 1991).

Nocturnal surface inversions are often associated with a boundary-layer wind speed maximum or low-level jet (Drake \& Farrow, 1988), resulting in much faster insect displacements than would occur at other potential flight altitudes. In a few cases it has been shown that the insects were primarily responding to air temperature rather than wind speed, because the layer was centred in the warmest air and was just above the level of the maximum wind speed (Schaefer, 1976; Drake, 1985), but more examples of this sort are required.

In contrast, several authors have reported cases where nocturnal insect layers were more clearly associated with the altitude of a wind speed maximum rather than a temperature maximum (Wolf et al., 1986; Beerwinkle et al., 1994; Riley et al., 1995; Feng et al., 2004, 2005). Wolf et al. (1986) for example, found that insects were flying preferentially in stable air near the centreline of a low-level jet, rather than at heights determined by variables such as temperature, relative humidity and wind direction. If anything, layers seemed to be located at the base of the inversion rather than in the warmest air (Westbrook et al., 1987). Some large nocturnal migrants can evidently detect regions of high wind speed, and they can also take up particular headings with respect to wind direction (e.g. down-wind orientation), but it is not at all clear how this feat is achieved (Riley \& Reynolds, 1986; Riley, 1989). In developed areas of the world such as southern Britain the plethora of lights on the ground may provide an easily observable pattern of visual cues allowing the detection of wind drift. However, the common alignment of insects with respect to wind, observed under very low illumination levels (e.g. moonless nights in West Africa), has lead to speculation that the insects may be able to use nonvisual cues such as anisotropic turbulence to detect wind velocity (Riley \& Reynolds, 1986; Riley, 1989). Small-scale anisotropic turbulence at altitude is primarily caused by Kelvin-Helmholtz waves generated at a stable atmospheric interface under conditions of strong wind shear, and if these cues are used one might expect insect layers to be associated with shear zones and, in fact, this has sometimes been reported (Schaefer, 1976). Experience with entomological scanning radar studies, in places such as West Africa, gives the impression that occasions with good insect layering were frequently also those where the migrants showed strong common orientation patterns (D.R. Reynolds, unpublished) so it is possible that non-visual, turbulence-related cues may inform migrants of zones of maximum wind speed and provide information on the wind direction. Some preliminary evidence indicates that the maintenance of common orientation by nocturnal insect migrants in the UK may also be associated with the presence of layering (A.S. Edwards, 2004, unpublished report).

In the UK, nocturnal insect migrants will often be faced with sub-optimal temperatures, even during summer, and in fact there is a strong positive relationship between air temperature and numbers of night-flying insects detected by vertical-looking radar (Smith et al., 2000). Therefore one might expect that, after the initial take-off and ascent phase, the height of flight would be heavily influenced by air temperature. The preliminary findings reported here indicate that this is the case, with nocturnal insect layers coinciding with local temperature maxima, located at the top of either a surface temperature inversion (see also Chapman et al., 2002b, 2003) or a higher altitude inversion (e.g. one caused by large-scale subsidence within a high pressure region), although to demonstrate this conclusively one would need radiosonde ascents near the radar site while the layer was present. The diversity of species contributing to the layers seems to point to a general adaptation (or constraint) exhibited by migrant insects, rather than very species-specific thresholds for sustained flight pertaining to particular taxa.

In conclusion, it may be worth emphasizing that nocturnal layering events are more important than it might seem from their (relatively low) frequency of occurrence. This is because they often occur on nights which are particularly favourable to massive and sustained insect migrations, when there is likely to be considerable redistribution of populations within the UK, and perhaps between the UK and 
neighbouring areas of continental Europe. These events may be noteworthy due to the arrival in Britain of pests like P. xylostella (Chapman et al., 2002b), or other species which are of interest to ecologists or the general public.

\section{Acknowledgements}

The authors are grateful to $\mathrm{Mr}$ Peter Clark of the Mesoscale Modelling Group, Joint Centre for Mesoscale Meteorology, Reading, for providing the MetSim data. Professor J.R. Riley and a referee made some useful comments on a draft of the manuscript. Rothamsted Research receives grant-aided support from the Biotechnology and Biological Sciences Research Council (BBSRC). J.W. Chapman and A.D. Smith were supported by BBSRC grant 206/D15558, and C.R. Wood by a BBSRC/Met Office PhD CASE studentship.

\section{References}

Beerwinkle, K.R., Lopez, J.D., Witz, J.A., Schleider, P.G., Eyster, R.S. \& Lingren, P.D. (1994) Seasonal radar and meteorological observations associated with nocturnal insect flight at altitudes to 900 metres. Environmental Entomology 23, 676-683.

Browning, K.A. (1981) Ingestion of insects by intense convective updraughts. Antenna 5, 14-17.

Campistron, B. (1975) Characteristic distributions of angel echoes in the lower atmosphere and their meteorological implications. Boundary-Layer Meteorology 9, 411-426.

Chapman, J.W., Smith, A.D., Woiwod, I.P., Reynolds, D.R. \& Riley, J.R. (2002a) Development of vertical-looking radar technology for monitoring insect migration. Computers and Electronics in Agriculture 35, 95-110.

Chapman, J.W., Reynolds, D.R., Smith, A.D., Riley, J.R., Pedgley, D.E. \& Woiwod, I.P. (2002b) High-altitude migration of the diamondback moth Plutella xylostella to the U.K.: a study using radar, aerial netting and ground trapping. Ecological Entomology 27, 641-650.

Chapman, J.W., Reynolds, D.R. \& Smith, A.D. (2003) Verticallooking radar: a new tool for monitoring high-altitude insect migration. BioScience 53 (5), 503-511.

Chapman, J.W., Reynolds, D.R., Smith, A.D., Smith, E.T. \& Woiwod, I.P. (2004) An aerial netting study of insects migrating at high-altitude over England. Bulletin of Entomological Research 94, 123-136.

Cullen, M.J.P., Davies, T., Mawson, M.H., James, J.A., Coulter, S.C. \& Malcolm, A. (1997) An overview of numerical methods for the next generation UK NWP and climate model. pp. 425-444 in Lin, C., Laprise, R. \& Ritchie, H. (Eds) Numerical methods in atmospheric and oceanic modelling (the André J. Robert Memorial Volume). Ottawa, Canadian Meteorological and Oceanographic Society.

Dickinson, A. (1999) Description of UKMO Atmospheric Model. Paper 1, MOSAC-4, 9 September 1999. Bracknell, UK, Meteorological Office. $10 \mathrm{pp}$.

Dingle, H. (1996) Migration: the biology of life on the move. 474 pp. Oxford, UK, Oxford University Press.

Drake, V.A. (1984) The vertical distribution of macro-insects migrating in the nocturnal boundary layer: a radar study. Boundary-Layer Meteorology 28, 353-374.

Drake, V.A. (1985) Radar observations of moths migrating in a nocturnal low-level jet. Ecological Entomology 10, 259-265.
Drake, V.A. (2002) Automatically operating radar for monitoring insect pest migrations. Entomologica Sinica 9 (4), 27-39.

Drake, V.A. \& Farrow, R.A. (1983) The nocturnal migration of the Australian plague locust Chortoicetes terminifera (Walker) (Orthoptera: Acrididae): quantitative radar observations of a series of northward flights. Bulletin of Entomological Research 73, 567-585.

Drake, V.A. \& Farrow, R.A. (1988) The influence of atmospheric structure and motions on insect migration. Annual Review of Entomology 33, 183-210.

Drake, V.A. \& Gatehouse, A.G. (Eds) (1995) Insect migration: tracking resources through space and time. Cambridge, Cambridge University Press.

Drake, V.A. \& Rochester, W.A. (1994) The formation of layer concentrations by migrating insects. pp. 411-414 in Proceedings of 21st Conference on Agricultural and Forest Meteorology-11th Conference on Biometeorology, March 7-11 1994, San Diego, California. Boston, American Meteorological Society.

Feng, H.-Q., Wu, K.-M., Cheng, D.-F. \& Guo, Y.-Y. (2003) Radar observations of the autumn migration of the beet armyworm Spodoptera exigua (Lepidoptera: Noctuidae) and other moths in northern China. Bulletin of Entomological Research 93, 115-124.

Feng, H.-Q., Wu, K.-M., Cheng, D.-F. \& Guo, Y.-Y. (2004) Spring migration and summer dispersal of Loxostege sticticalis (Lepidoptera: Pyralidae) and other insects observed with radar in northern China. Environmental Entomology 33, 1253-1265.

Feng, H.-Q., Wu, K.-M., Ni, Y.-X., Cheng, D.-F. \& Guo, Y.-Y. (2005) High altitude windborne transport of Helicoverpa armigera (Lepidoptera: Noctuidae) and other moths in mid summer in northern China. Journal of Insect Behavior (in press).

Gatehouse, A.G. (1997) Behavior and ecological genetics of wind-borne migration by insects. Annual Review of Entomology 42, 475-502.

Gossard, E.E. \& Strauch, R.G. (1983) Biological targets and their role in radar backscatter. pp. 171-178 in Radar observations of clear air and clouds. Amsterdam, Elsevier.

Greenbank, D.O., Schaefer, G.W. \& Rainey, R.C. (1980) Spruce budworm (Lepidoptera: Tortricidae) moth flight and dispersal: new understanding from canopy observations, radar, and aircraft. Memoirs of the Entomological Society of Canada 110, 1-49.

Johnson, C.G. (1969) Migration and dispersal of insects by flight. 763 pp. London, Methuen.

Mel'nichenko, A.N. (1936) [Regularities of mass flying of the adult Loxostege sticticalis L., and the problem of prognosis of their flight migrations]. Bulletin of Plant Protection, Leningrad. Series 1, Entomology, no. 17, 56 pp. (See Review of Applied Entomology (A) 24, 816-817.)

Ottersten, H. (1970) Radar angels and their relationship to meteorological factors. Final Report. Försvarets Forskningsanstalt, Stockholm, FOA Reports vol. 4, no. 2, 1-33.

Palmqvist, G. (2000) Intressanta fynd av storfjärilar (Macrolepidoptera) i Sverige 2000. [Remarkable records of Macrolepidoptera in Sweden 2000.] Entomologisk Tidskrift $122(1-2), 41-55$.

Pedgley, D.E. (1982) Windborne pests and diseases: meteorology of airborne organisms. 250 pp. Chichester, Ellis Horwood.

Reynolds, D.R. \& Riley, J.R. (1997) The flight behaviour and migration of insect pests: radar studies in developing countries. 
NRI Bulletin no. 71. 114 pp. Chatham, UK, Natural Resources Institute.

Richter, J.H., Jensen, D.R., Noonkester, V.R., Kreasky, J.B., Stimmann, M.W. \& Wolf, W.W. (1973) Remote radar sensing: atmospheric structure and insects. Science 180, 1176-1178.

Riley, J.R. (1989) Orientation by high-flying insects at night: observations and theories. Orientation and navigation-birds, humans and other animals. Conference of the Royal Institute of Navigation, Cardiff, 6-8 April 1989. London, The Royal Institute of Navigation.

Riley, J.R. \& Reynolds, D.R. (1979) Radar based studies of the migratory flight of grasshoppers in the middle Niger area of Mali. Proceedings of the Royal Society, B 204, 67-82.

Riley, J.R. \& Reynolds, D.R. (1986) Orientation at night by highflying insects. pp. 71-87 in Danthanarayana, W. (Ed.) Insect flight: dispersal and migration. Berlin, Springer-Verlag.

Riley, J.R., Cheng, X.N., Zhang, X.X., Reynolds, D.R., Xu, G.M., Smith, A.D., Cheng, J.Y., Bao, A.D. \& Zhai, B.P. (1991) The long distance migration of Nilaparvata lugens (Stål) (Delphacidae) in China: radar observations of mass return flight in the autumn. Ecological Entomology 16, 471-489.

Riley, J.R., Reynolds, D.R., Smith, A.D., Edwards, A.S., Zhang, X.-X., Cheng, X.-N., Wang, H.-K., Cheng, J.-Y. \& Zhai, B.-P. (1995) Observations of the autumn migration of the rice leaf roller Cnaphalocrocis medinalis (Lepidoptera: Pyralidae) and other moths in eastern China. Bulletin of Entomological Research 85, 397-414.

Russell, R.W. \& Wilson, J.W. (1997) Radar-observed "fine-lines" in the optically clear boundary layer: reflectivity contributions from aerial plankton and its predators. Boundary-Layer Meteorology 82, 235-262.

Russell, R.W. \& Wilson, J.W. (2001) Spatial dispersion of aerial plankton over east-central Florida: aeolian transport and coastline concentrations. International Journal of Remote Sensing 22, 2071-2082.

Sauvageot, H. \& Despaux, G. (1996) The clear-air coastal vespertine radar bands. Bulletin of the American Meteorological Society 77, 673-681.

Schaefer, G.W. (1976) Radar observations of insect flight. pp. 157-197 in Rainey, R.C. (Ed.) Insect flight. Symposia of the Royal Entomological Society, No. 7. Oxford, Blackwell.

Smith, A.D., Riley, J.R. \& Gregory, R.D. (1993) A method for routine monitoring of the aerial migration of insects by using a vertical-looking radar. Philosophical Transactions of the Royal Society, B 340, 393-404.

Smith, A.D., Reynolds, D.R. \& Riley, J.R. (2000) The use of vertical-looking radar to continuously monitor the insect fauna flying at altitude over southern England. Bulletin of Entomological Research 90, 265-277.

Thomas, A.A.G., Ludlow, A.R. \& Kennedy, J.S. (1977) Sinking speeds of falling and flying Aphis fabae Scopoli. Ecological Entomology 2, 315-326.

Vaughn, C.R. (1985) Birds and insects as radar targets: a review. Proceedings of the Institute of Electrical and Electronic Engineers 73, 205-227.

Westbrook, J.K., Wolf, W.W., Pair, S.D., Sparks, A.N. \& Raulston, J.R. (1987) Empirical moth flight behavior in the nocturnal planetary boundary layer. pp. 263-264 in Proceedings of 18th Conference on Agricultural and Forest Meteorology-8th Conference on Biometeorology and Aerobiology, September 15-18, 1987, W. Layfayette, Indiana. Boston, American Meteorological Society.
Wolf, W.W., Westbrook, J.K. \& Sparks, A.N. (1986) Relationships between radar entomological measurements and atmospheric structure in south Texas during March and April 1982. pp. 84-97 in Sparks, A.N. (Ed.) Long-range migration of moths of agronomic importance to the United States and Canda: specific examples of the occurrence and synoptic weather patterns conducive to migration. US Department of Agriculture, Agricultural Research Service ARS-43.

\section{Appendix 1 \\ Description of the 'Layer Quality' modules}

To search the vertical-looking radar database for likely layers, a module (SeekLayers) is run within Microsoft Access. This creates a Table which contains both target numbers and 'percentage above threshold' data (for each of the radar sampling heights) for each 5-min radar collection period. Various parameters are calculated and finally a Layer Quality (LQ) code number is assigned which indicates the likelihood of a layer. Experience has shown that it is better to include all analysable targets, regardless of their correlation coefficient (see Methods) in the preliminary data processing.

The rules underlying the Layer Quality (LQ) assignment are as follows.

$\mathrm{LQ}=0 \quad$ Radar not operating.

$\mathrm{LQ}=1 \quad$ 'Percentage above threshold' values $>10 \%$ in all gates. When the percentage above threshold is $>10 \%$, the target numbers are likely to be seriously affected by interference, and are considered to be unreliable. In particular, a uniformly high percentage above threshold in all gates is virtually always caused by precipitation, and it is important to exclude these periods from the analysis. (The module does attempt, however, to identify occasions when an insect layer is present, but masked by inter-target interference-see below, $\mathrm{LQ}=7$.)

Altitudes higher than the point at which the percentage above threshold falls below $10 \%$ are subsequently inspected for Layer Qualities of 2-6, using targets numbers.

$\mathrm{LQ}=2$ No layer, as no (unit) increase in analysable target numbers with altitude.

$\mathrm{LQ}=3$ No layer. The number of targets in each of the gates inspected $\leqslant 5$ or the variation in target numbers $\leqslant 5$. This excludes Gate 1 ( 150 to $195 \mathrm{~m}$ ) because there are often high numbers of targets at low altitudes for reasons unrelated to the layering of migrants.

$\mathrm{LQ}=4 \quad$ Poorly-defined layer. A peak (in a single gate) has been detected, containing more than 5 targets, but less than $15 \%$ of the total number of targets detected in the profile.

$\mathrm{LQ}=5 \quad$ Layer. A peak (in a single gate) has been detected, containing between $15 \%$ and $25 \%$ of the total targets detected in the profile; or a peak containing $>25 \%$ of the total targets but composed of $<10$ targets.

$\mathrm{LQ}=6 \quad$ Well-defined layer. A peak (in a single gate) has been detected with at least 10 targets, and with at least $25 \%$ of total targets.

If target numbers are unreliable due to inter-target interference the module then inspects the percentage above threshold data for evidence of a layer. 
$\mathrm{LQ}=7 \quad$ Possible layer. 'Percentage above threshold' values $>10 \%$ in all gates, and there is a rise of at least $10 \%$ within the profile. The $L Q=7$ output is useful when very high insect densities create inter-target interference, preventing the analysis of individual targets. Occasionally an $\mathrm{LQ}=7$ may also be generated by precipitation in the high altitude gates, but these occasions can be identified and excluded from analysis because they are usually singletons, preceded and followed by periods with low LQ scores.

The threshold values used by the algorithm to set LQ are of necessity somewhat arbitrary, based on experience of profiles and knowledge of the radar's characteristics. During testing, and the current analysis, they have appeared to be appropriate.

In the second stage of the process, a module (SheetModule) is used to produce a summary table which presents the LQ values for each sample period (normally collected at 15-min intervals) for each of the days in a calendar month. LQ values below 4 are omitted making the table easier to study. In fact, experience of the analysis of nocturnal layers shows that really interesting layering occasions will have runs of LQ values of 6 interspersed by a few $5 \mathrm{~s}$, and the occasional 4 or 7.

Finally, the presence and nature of layering during the identified nights of interest are examined in detail by exporting the data files generated from SeekLayers to Microsoft Excel. Viewing a sequence of individual vertical profiles (of insect numbers or percentage above threshold data) gives a graphic impression of the development and decay of layers on these particular nights.

(Accepted 7 January 2005) (C) CAB International, 2005 